\title{
Solar investment risk mitigation - are we all on the same page?
}

\author{
Thomas C. Sauer ${ }^{*}$ \\ EXXERGY GmbH, Frankfurt am Main, Germany
}

\author{
Received: 31 January 2019 / Received in final form: 25 April 2019 / Accepted: 10 May 2019
}

\begin{abstract}
Currently, the PV solar sector represents approx. $2 \%$ of worldwide annual electricity production (https://webstore.iea.org/world-energy-outlook-2018), and therefore, is just at the verge of becoming visible in most countries. As the PV sector becomes increasingly visible to the next order of magnitude sometime in future, representing $20 \%$ in the electricity mix and beyond, it is now a good time to discuss reliability, predictability, and performance of $\mathrm{PV}$ power plants and as a consequence, the improvement potential for financial returns. Building on this train of thought, this article will provide a short introduction of PV power plant risks, predominantly related to technical performance. The question of risk mitigation measures will then be discussed: On the one side, quality assurance is a viable risk mitigation measure. However, even with quality assurance measures implemented, there are limitations when it comes to backstopping financial losses in the event that the performance deteriorates more than predicted and warranted by the manufacturers, or if the manufacturers or EPC's are no longer in business when incidental power degrades beyond calculated limits. Insurance solutions seem to provide an additional risk mitigation measure. Most insurance solutions on the market, however, only cover against externally induced risk exposures, e.g. severe weather, theft. Most of these insurance solutions follow a certain minimum standard. A few insurance products offer performance insurances where general cover is less standardized. All this triggers the question of how to look at insurance solutions. The interests of an insurance company are generally different than those of the insured stakeholders. These different viewpoints will be discussed, and selected warranty and insurance aspects will be considered. Recently, approximately 3500 insurance claim cases were statistically analyzed (http://www.pvstatlab.rwth-aachen.de/index.php/ PVScan-project.html). Selected results of this analysis will be discussed. The article closes with an outlook of how insurers can likewise mitigate their risk exposure - in the end, insurers are only as good as the balance of the solvency resulting from their business model, or in the terminology of the insurance sector, the loss ratio must be at an acceptable level. This is where IECRE, the IEC System for Certification to Standards Relating to Equipment for Use in Renewable Energy Applications (https://www.iecre.org/), offering an international standard for certification - and in future - a rating system for PV power plants on a system level comes into play.
\end{abstract}

Keywords: bankability / claim case report / conformity assessment / IECRE conformity assessment system / insurance claim case / performance warranty insurance / PV power plant rating / rating system / risk management / standardization

\section{Introduction}

The number of photovoltaic installations worldwide has increased exponentially over the last 10 years. 2017 saw the largest ever increase in renewable power capacity, falling costs, increases in investment and advances in enabling technologies, according to the Renewables 2018 Global

\footnotetext{
* e-mail: tcs@exxergy.com
}

Status Report, by REN21. Solar photovoltaic (PV) capacity installations were nearly double those of wind power, adding more net capacity than coal, natural gas and nuclear power combined.

While this is great news for the renewables industry, complex solar PV equipment and systems raise questions for customers and investors, such as how can they know that a system really is good, and how much more would they be willing to invest to ensure they get a higher quality system that actually yields the projected technical and financial performance - or even more over the long haul? 


\section{General thoughts on risk mitigation measures}

There are various technical reasons why a PV power plant can underperform or completely fail. Besides the technical effects, most importantly, underperformance of a PV power plant negatively effects the shareholders' returns in the first instance. The equity investors are first to suffer financially from underperforming assets. In some cases, technical performance deteriorations are so severe that even the debt side of the financing scheme is negatively affected to the extent that the redemption of the loan and part of the interest payment can no longer be serviced.

The causes for PV power plant asset underperformance are many. A review of the cost development of turn-key PV power plants over the last 20 years is very impressive. However, whether some stakeholders involved in the value chain of realizing a PV power plant exercise poor quality practices because of distressed financials is another question.

Be that as it may, as a result of a distressed financial situation of a PV power plant project, the bank typically holds a strong position to exploit the asset, if taking recourse from the senior lender is not an option. When it comes to performance deterioration, besides considerations regarding the sufficiency of quality assurance measures the main question is whether-and if so, how far-the gap between planned and current performance can be compensated for, either by making warranty claims against the manufacturer or by asking coverage from an insurance wrap.

Insurances differentiate greatly between externally and internally induced damage that causes underperformance or other losses. Internally induced damage is typically associated with quality issues that occurred at least once during the lifetime of a project-from inception through decommissioning.

Regardless, in the given damage event, particularly in the case of internally induced damages, the key question remains whether compensation for performance losses can be claimed or not.

\section{Risk mitigation: considerations on quality assurance measures}

As part of an overall PV power plant project due diligence, the financial sector currently bases its investment decisions, lending commitments, etc. on technical assessment reports. These assessment reports also outline all measures that have been taken during the project execution to assure the quality of the end product. Up to now, no encompassing international standards existed, either when it comes to the quality assurance or to the assessment report itself. Depending on the assessor, these reports vary significantly in terms of thoroughness, accuracy, completeness, reliability, validity, transparency etc. Two important consequences derive from this situation: (1) the quality assurance measures may or may not be sufficient to ensure that the planned performance will actually materialize throughout the planning horizon of typically 20 and more years. Especially when it comes to the re-sale of the asset in the secondary market, the originally applied quality measures are an important factor for the fungibility of an asset as available documentation may be partly missing. (2) The diversity of technical assessment reports (lacking any standards) results in a high workload on the receiving side (e.g. banks), and more importantly, in uncertainties evaluating the true risk exposure of a PV power plant project. Other aspects indirectly related to quality assurance are (1) the lack of consistency of tenders among government bodies and other institutions inviting participation in tenders oftentimes, the quality requirements per se as well as the quality assurance measures are not precisely specified and (2) the untapped potential of optimized PV power plant performance resulting from inaccurate work results.

This status quo motivated the member bodies of the International Electrotechnical Commission (IEC) to create an IEC conformity assessment system for certification to standards relating to equipment for use in Renewable Energy applications, in brief, IECRE [1]. With the adoption of the IECRE certification system, quality assurance is given a common platform on a system level, a minimum standard, to enable fair and efficient competition.

These minimum standards are supplemented by IECRE plans to develop a technical rating system for PV power plants. This rating system will be essential to enabling financial stakeholders to get a nuanced picture of the quality of a PV power plant beyond minimum the requirements, providing a complimentary grading system similar to those common in the financial realm. The project developing the PV power plant rating system will start in Q2 of 2019. According to plan, the resulting rating system will be submitted for ballot to the member bodies of IECRE in 2020. More details will be discussed in Section 6.

\section{Considerations on selected warranty insurance aspects}

Insurers who cover the risk of inherent technical defects and their economic consequences should most likely have an interest in good quality assurance, else an insurers risk mitigation must be ensured by other means. This is especially applicable for insurers offering performance warranty insurance solutions. Generally, two models are supposedly available on the market to secure a minimum yield of a PV power plant:

- Component manufacturer related: The insurance covers the manufacturer's warranty services (e.g. replacement of inherently defective components) in the event of the insured manufacturer's insolvency. Some insurance solutions also offer a warranty cover for the event that the manufacturer rejects the warranty service or disputes the obligation to perform in whole or in part (warranty failure insurance). The warranty failure insurance 
10000

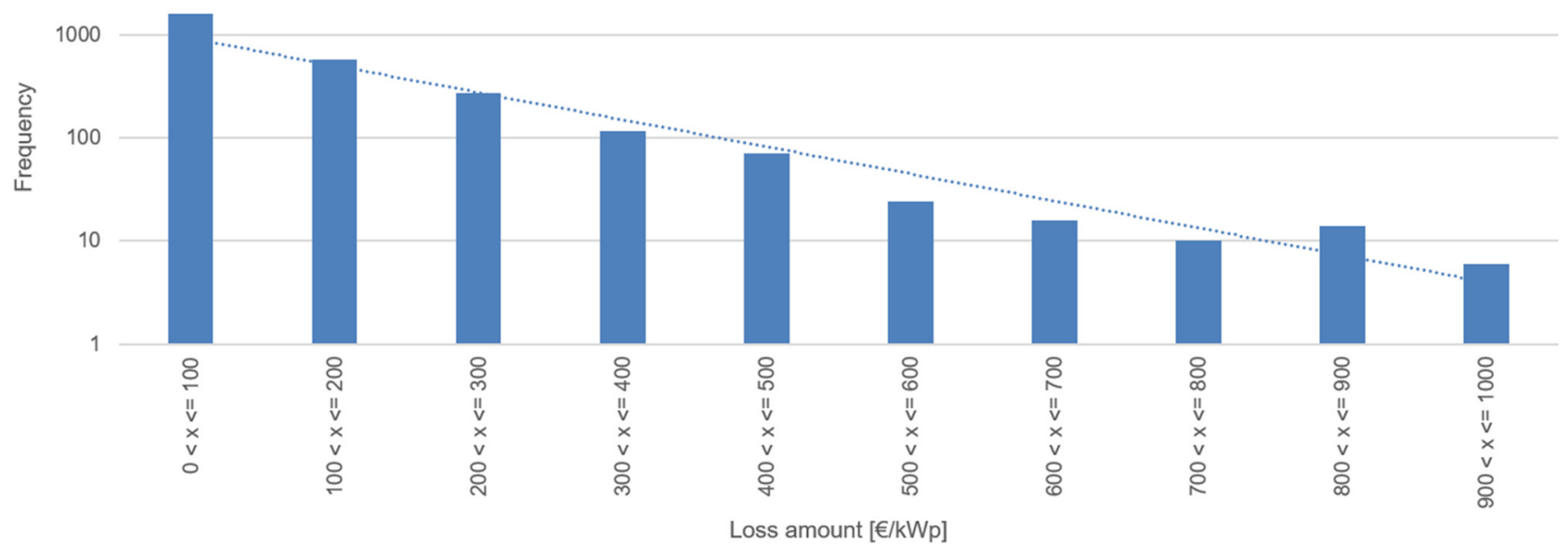

Fig. 1. Distribution of amount of loss classification.

typically compensates the (re-) purchase value or the book value of the defect components plus in some instances the replacement costs and/or loss of revenue.

- Project related: Depending on the scope of the insurance, (partial) compensation for losses can be covered, such losses deriving either from technical issues (e.g. excessive performance degradation) or from radiation-related losses. The compensation varies and can be provided in cash or in kind (performance warranty insurance). The performance warranty insurance typically compensates for an inferior energy yield caused by inherent module defects. The trigger for the insurance to become liable varies. As an example, manufacturer insolvency and an inherent defect related performance shortfall of at least $10 \%$ are basic triggers. In addition, a maximum limit of cover is typically provided. The cover payout can be provided in cash (loss of revenue) or in kind (replacement of defect components) or by a combination of both.

Regardless of the insurance solution, it is important to understand the limitations, exclusions, caveats, prerequisites etc. to be met as well as other relevant insurance terms and conditions in detail. Sufficient documentation is certainly of the essence. These details are relevant for the assessment of the actual effectiveness of this risk mitigation tool and hence, viably concluding whether a tangible risk transfer is taking place in the perceived insured event.

\section{Insurance claim cases - selected insights}

A study analyzing the root causes of insurance claim cases has been conducted. 4 of 13 invited insurance companies responded to an inquiry providing information and data related to claim cases. As a result, 3666 insurance claim cases have been analyzed in this study, all of which occurred in the Northern hemisphere at latitudes North of $35^{\circ}$. The following outlines an excerpt of a detailed study [2].

The insurance claim records date from the time between January 2012 and June 2017 so that a history of 5.5 years of insurance claim cases was covered in the study. The average amount of loss was $2.6 \%$ of the investment, or 26 EUR per 1000 EUR investment. This number includes a significant number of cases in which no insurance cover was granted, and therefore, counts as " 0 " while damage still had to be assumed. The spread of damages where compensation has been granted, however, is significant with a peak value of more than $110 \%$ relative to investment (>1100 EUR per 1000 EUR investment). Looking at the relationship of damage to nameplate power, the maximum damage was $3250 € / \mathrm{kWp}$ installed capacity. Note that both maximum numbers originate from different claim cases. Not surprisingly, no linear correlation could be drawn for either relationship, neither for the damage amount versus investment nor for the damage amount versus the installed capacity. The decline in frequency of claimed damages over the amount of loss follows a nearly logarithmic relationship: Damage cases with high amounts of loss are rare whereas minor damage cases occur more frequently. Figure 1 shows the frequency of damage claim cases on a logarithmic scale as a distribution of the amount of loss data in $€ / \mathrm{kWp}$ for those approx. 3600 claim cases for which the amount of loss has been covered.

Going into more detail of the analysis, $24 \%$ of the insurance claim cases could not be analyzed by IT tools in terms of root cause analysis since the information available did not contain a taxonomy that could be evaluated with reasonable effort. Nearly $3 \%$ of the insurance claim cases had multiple causes, and because of the relatively small relevance will not be discussed here in further detail. $6.7 \%$ of the claim cases had neither a time stamp for the time of incident nor for the time of claim. Including cases with no time stamp (a total of 2676 claims, or $73 \%$ of all cases), $20 \%$ were caused by internal defects, and $65 \%$ by external 


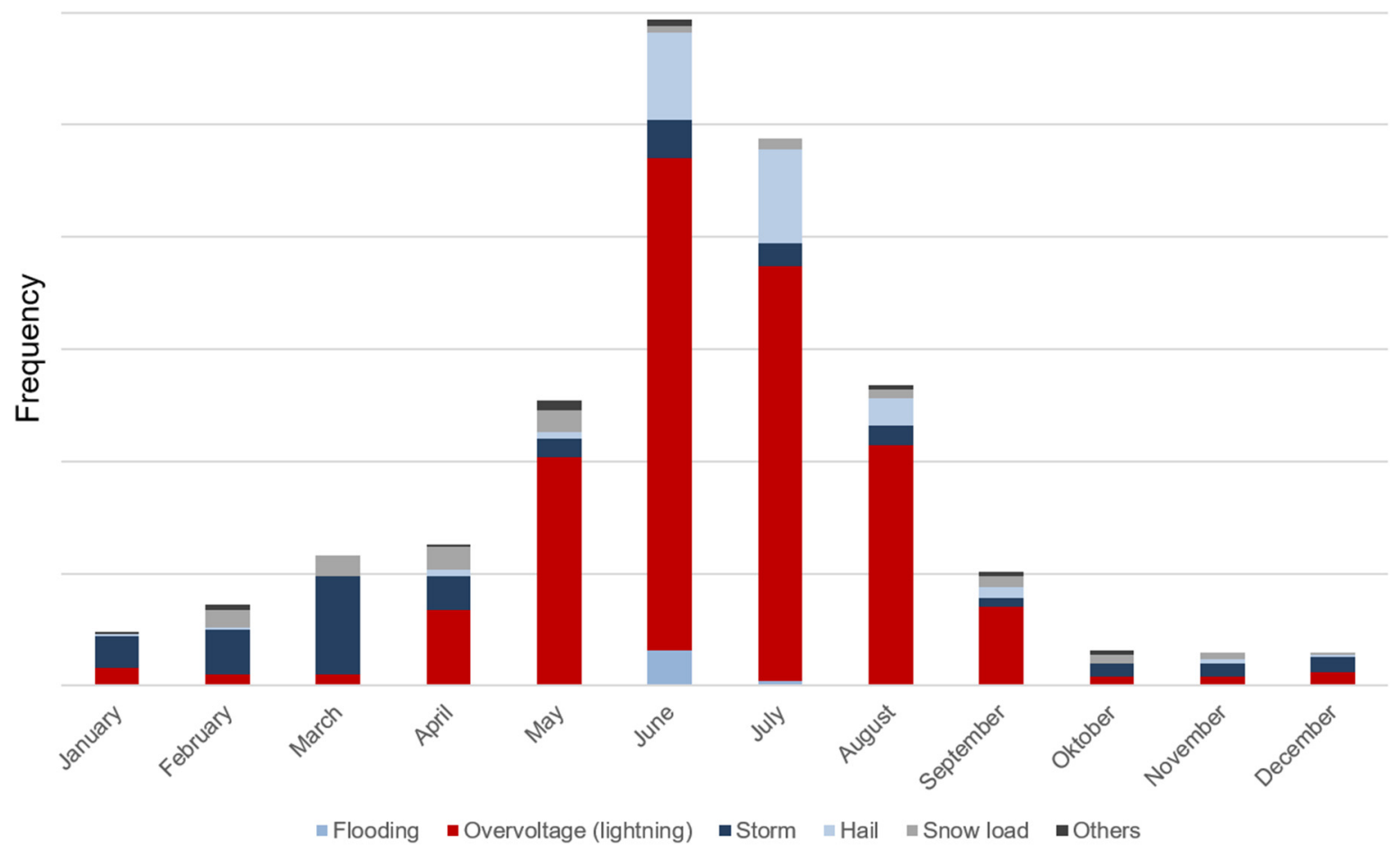

Fig. 2. Frequency of weather related causes of damage across seasons.

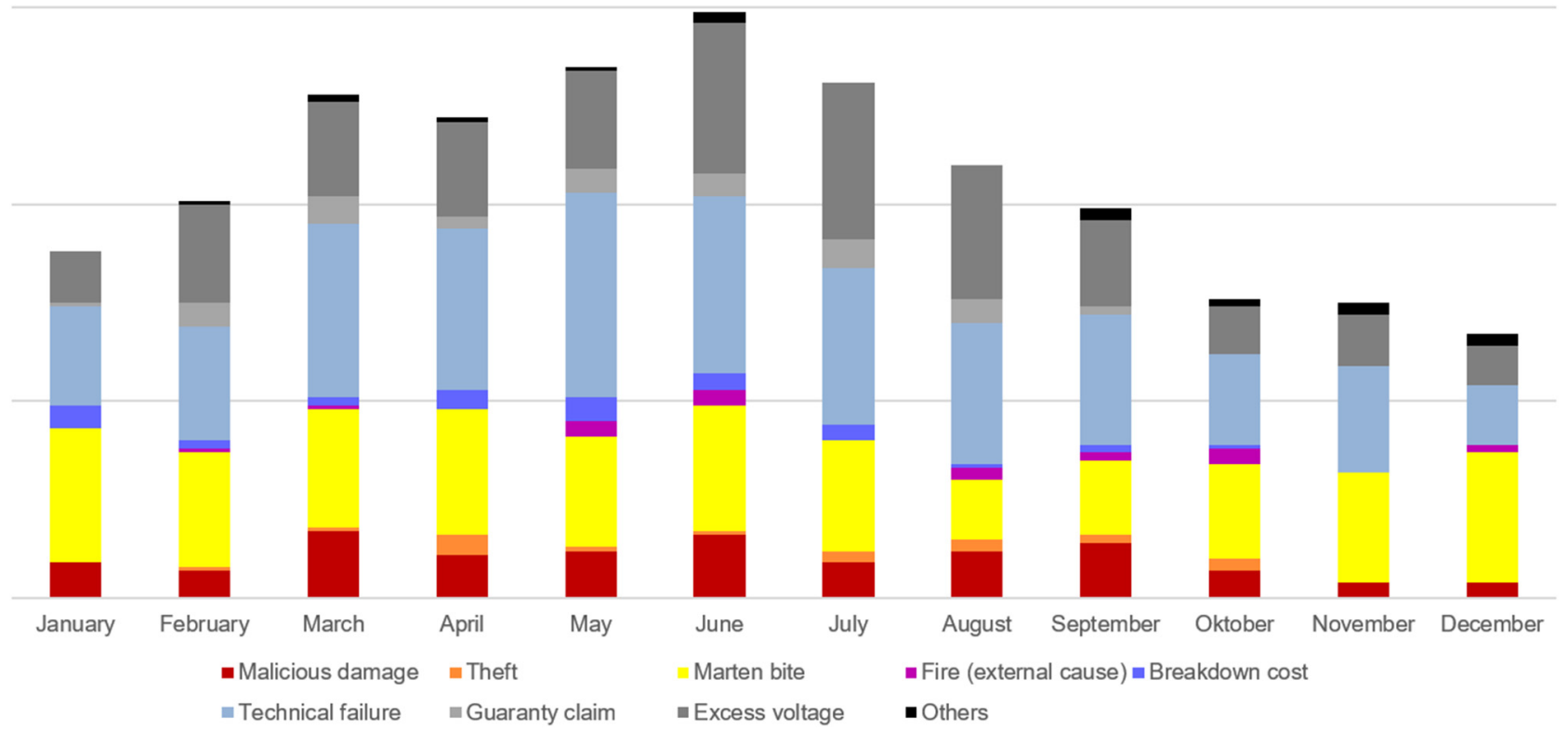

Fig. 3. Frequency of weather unrelated damage causes across seasons.

causes. Nearly $12 \%$ have been caused by excess voltage excluding lightning strikes. The analysis was inconclusive as to whether cases of excess voltage without proven lightning strikes were caused by lightning strikes or by internal defects or by grid instabilities. The remaining $3 \%$ of the claim cases were caused by other causes that are not reviewed in more detail.

Analyzing insurance claim cases that are caused by weather phenomena, the frequency of damage increased significantly in the months of May through August showing a significant peak in June, see Figure 2. This can commonly be explained by increased occurrence of convective weather activity and the resulting thunderstorms during the summer time.

Other causes of damages outlined in Figure 3 show that the distribution across seasons is more spread out with excess voltage showing a significant increase in the summer months. This phenomenon can be attributed by the fact that records were inconclusive as to whether the excess voltage came from the grid (cause may be lightning strikes 


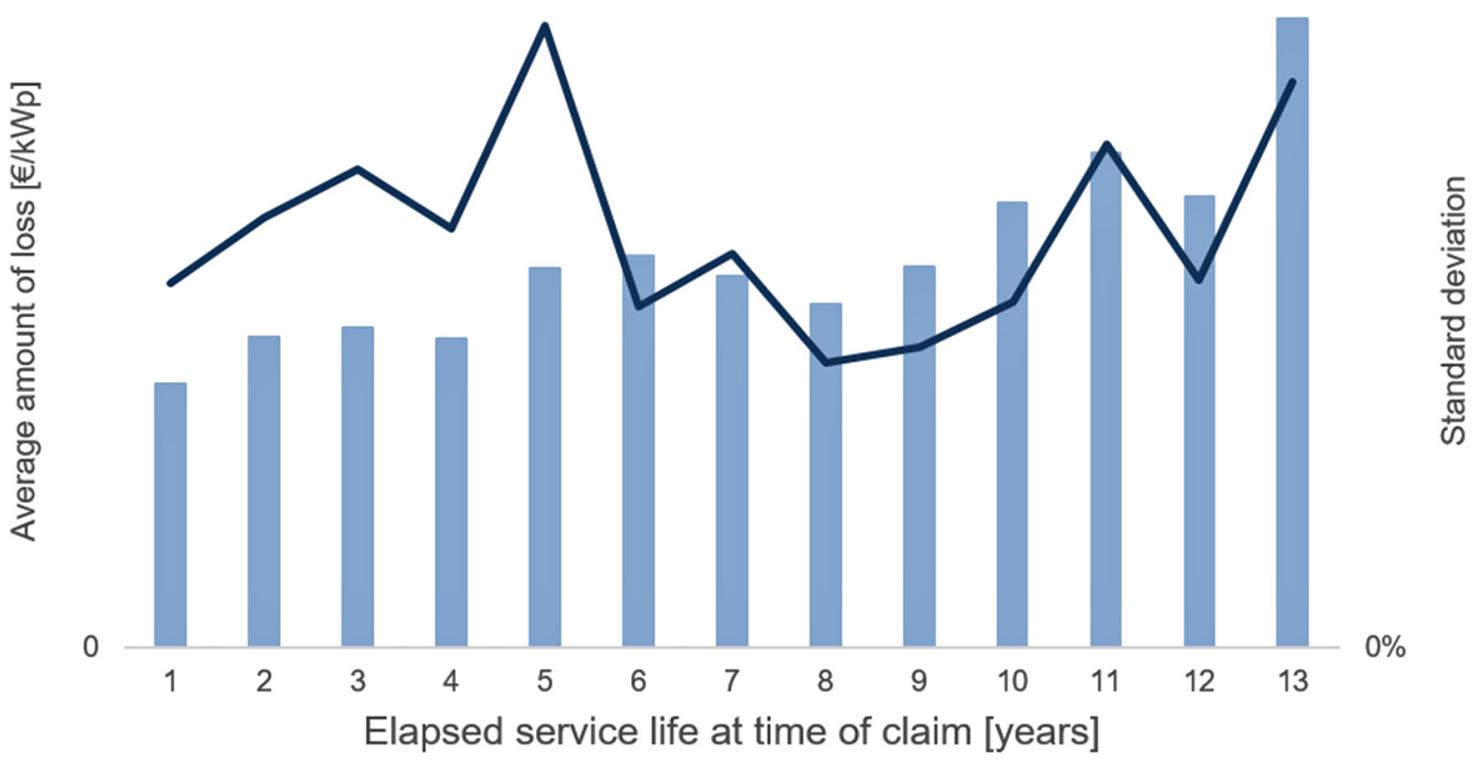

Average amount of loss $\longrightarrow$ Standard deviation

Fig. 4. Average amount of loss as a function of service life (all analyzed claim cases).

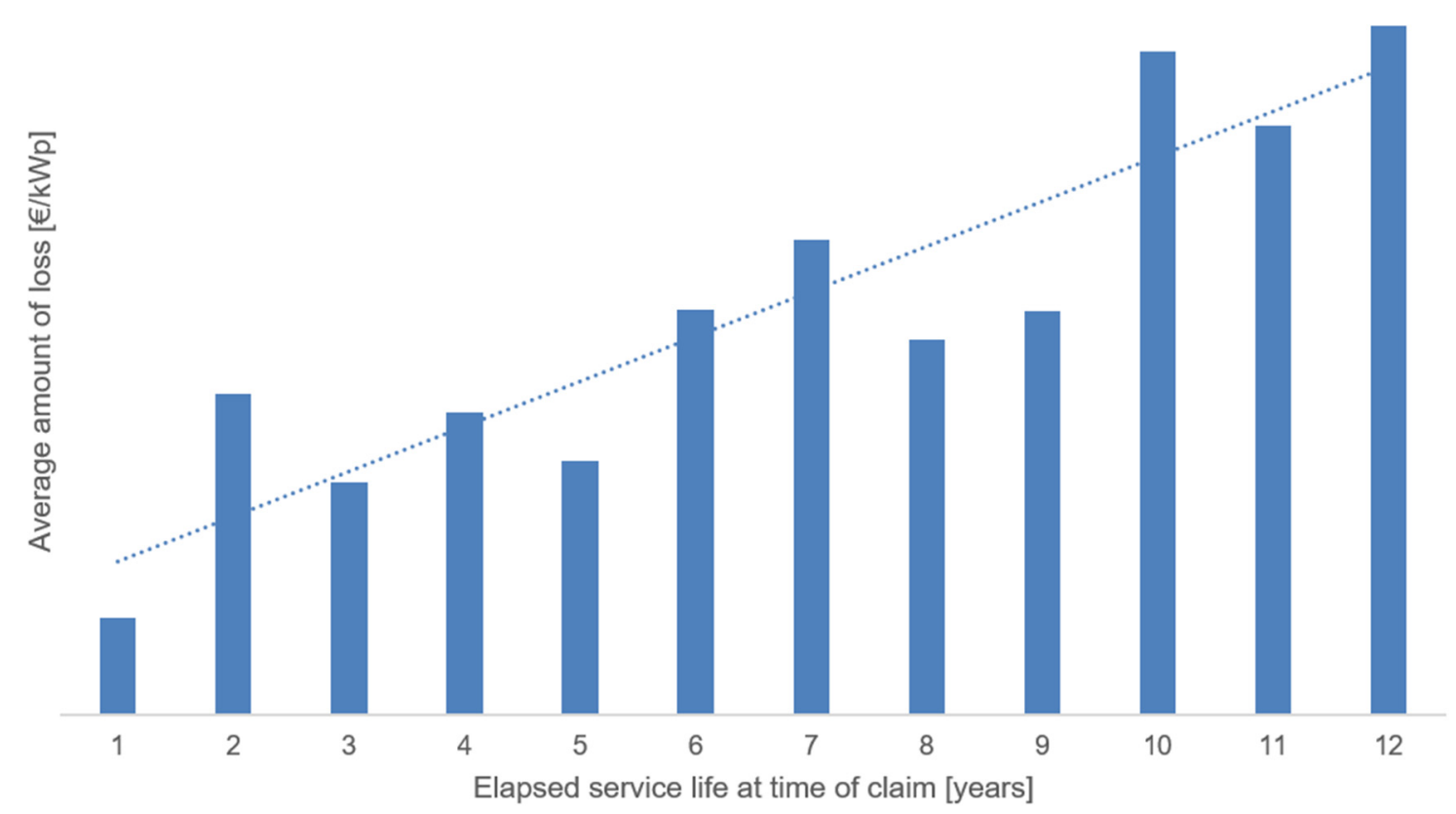

Fig. 5. Average amount of loss as a function of service life (internal defects).

as well) or from the system. Remarkable is the relatively high percentage of technical failures that can be attributed largely to internal defects of the system.

This conclusion leads to analyzing the average amounts of loss incidents over the service life of a PV power plant. A view in Figure 4 clearly evidences that - while standard deviation varies between $14.8 \%$ and $32.5 \%$, the average amount of loss significantly increases with service lifetime of a PV power plant.
This conclusion is even more evident when damages resulting from internal defects are analyzed. The trend is clear with average amounts of loss for damages resulting from internal defects being in the same range as the overall average amount of loss across all damage causes (Fig. 5).

Analyzing the breakdown of components affected as outlined in Figure 6 reveals that inverters and modules are the most prominent to be affected by damages, another significantly affected component is the cabling. 


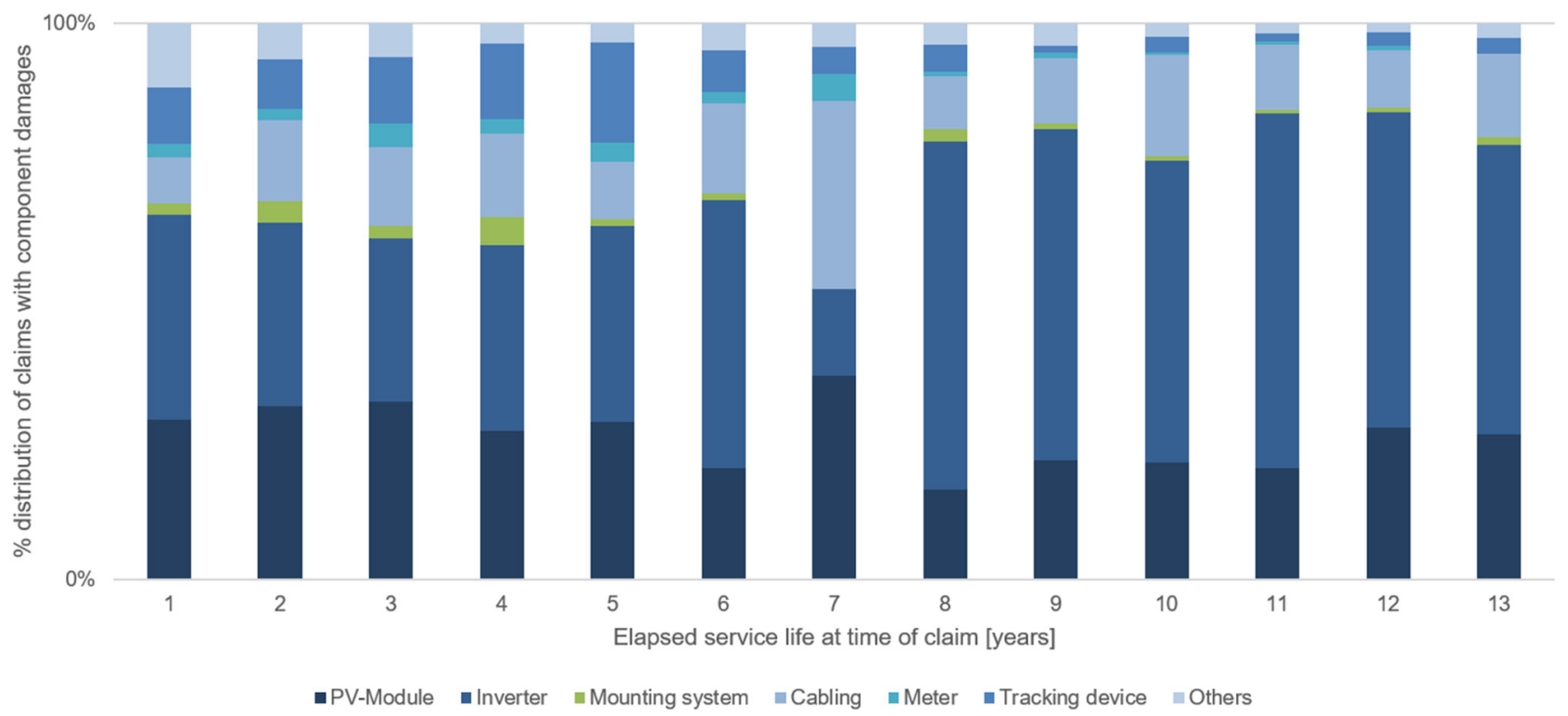

Fig. 6. Damaged components in $\%$ of all damages as a function of service life.

Looking into more detail related to the main damage causes by component (as far as specified), the following results have been identified:

- For modules in particular, external causes for damage were found to be malicious damage as the most frequent cause $(21.6 \%)$, followed by storm (18.6\%), and hail $(16.9 \%)$ while as an internal defect cause, technical failures account for a remarkable $18.4 \%$ of all cases.

- For inverters in particular, overvoltage is the most frequent cause of damage (60.8\%), 30.5\% of which have not been associated to lightning strikes. Technical failures accounted for $(31.9 \%)$ of all specified damages.

$-80.9 \%$ of all cabling damages result from marten bites.

- $93.4 \%$ of damage to communication equipment result from overvoltage, $20.6 \%$ of which have not been caused by lightning strikes. For damage to AC protective devices, the relative shares are $58.9 \%$ for damage cases due to overvoltage, of which $63.6 \%$ were not caused by lightning strikes.

Regarding the documentation of insurance claim cases, the effort of documentation increases with the amount of loss. The mostly used documentation classifications are (\%-numbers relative to the total number of claim cases $n=3666)$ :

- Evidence of insurance policy (98\%)

- Insurance claim report $(71 \%)$

- Quotation/invoice (44\%)

- Photography (28\%)

- Severe weather reports (18\%).

Other documentation includes expert opinions, particularly for cases with large amounts of loss. Naturally, the extent of documentation typically increases significantly with the average amount of damage. For amounts of more than $250 € / \mathrm{kWp}$, mostly 5 or more documentation classifications were provided.

Finally, the correlation between component manufacturers and damages has been studied by analyzing the quota of damage cases where devices have been affected by internal defects and by externally caused damages (where component quality had an influence on the damage) relative to the total volume components involved in damage by the respective manufacturer. Depending on the manufacturer, internal defects range from $0 \%$ to $90 \%$ for modules, and 25-100\% for inverters. However, it is important to note that this analysis only allows a first insight as it is not statistically conclusive. Nevertheless, it is obvious that quality assurance measures in the past have seemingly be insufficient, or else such high percentages would not be evident.

\section{Certification and technical rating - a new concept for risk mitigation}

A thorough risk management system requires a consistent and comprehensive approach. As outlined in Figure 7, a qualified and quantified risk analysis is a crucial element of a solid risk mitigation strategy.

As part of the IECRE certification and conformity assessment system, a technical rating system is currently under development. The status of the concept design reflects an initial rating to be established ideally during the inception phase of a PV power plant. After commissioning, further certificates and ratings on a PV power plant basis are foreseen to be issued on an annual basis or in the event of asset transfer to a new owner.

The rating concept is expected to address 3 levels:

- The basic ratings: Manufacturers, EPCs and operators are audited with regard to their product and service quality. The rating serves to classify the quality of the respective company.

- Project implementation supervision: Since the audits alone do not guarantee that the companies produce in accordance with the standards determined during the audit, monitoring of the entire development phase of the 


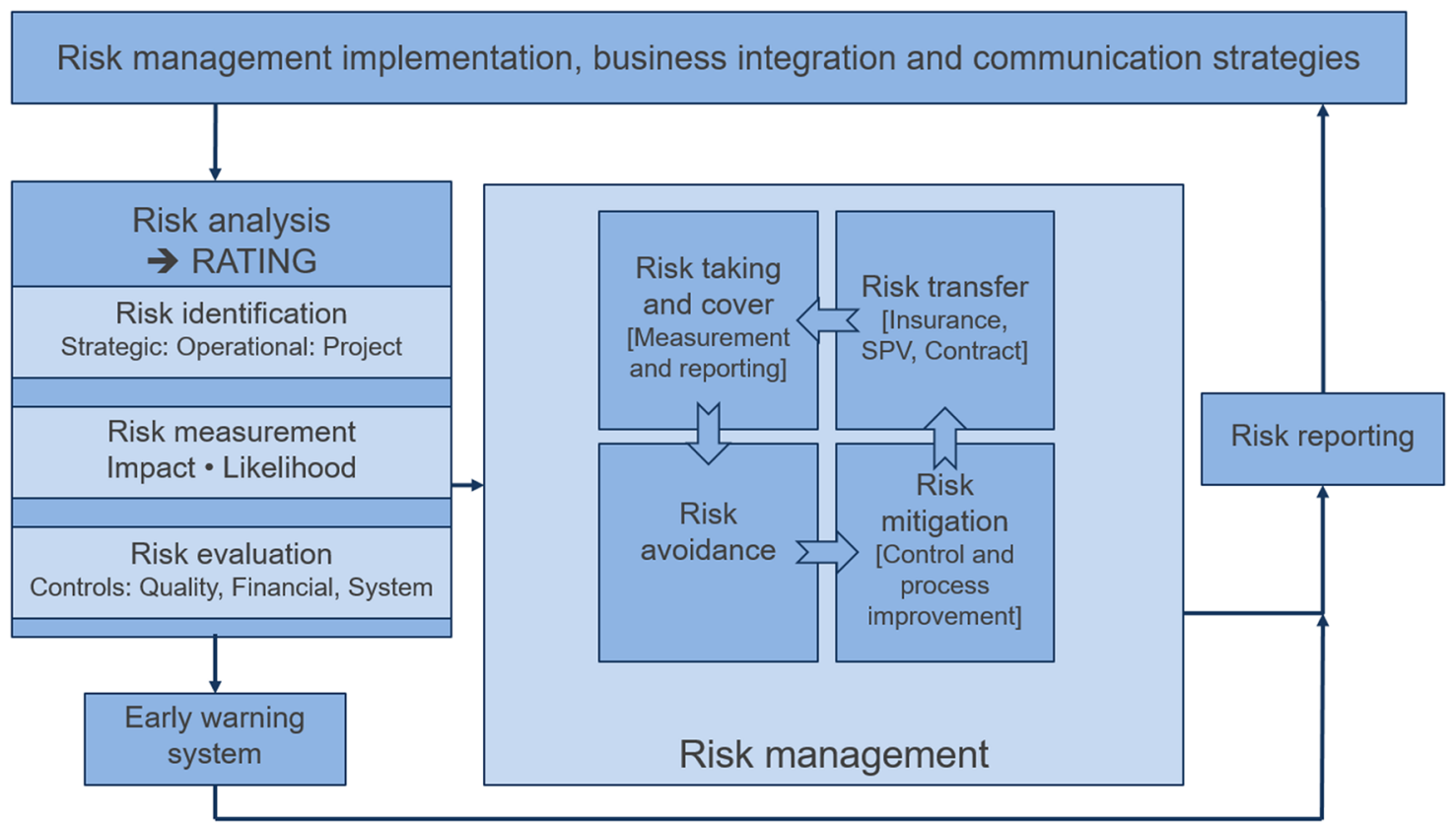

Fig. 7. Risk management strategy circle.

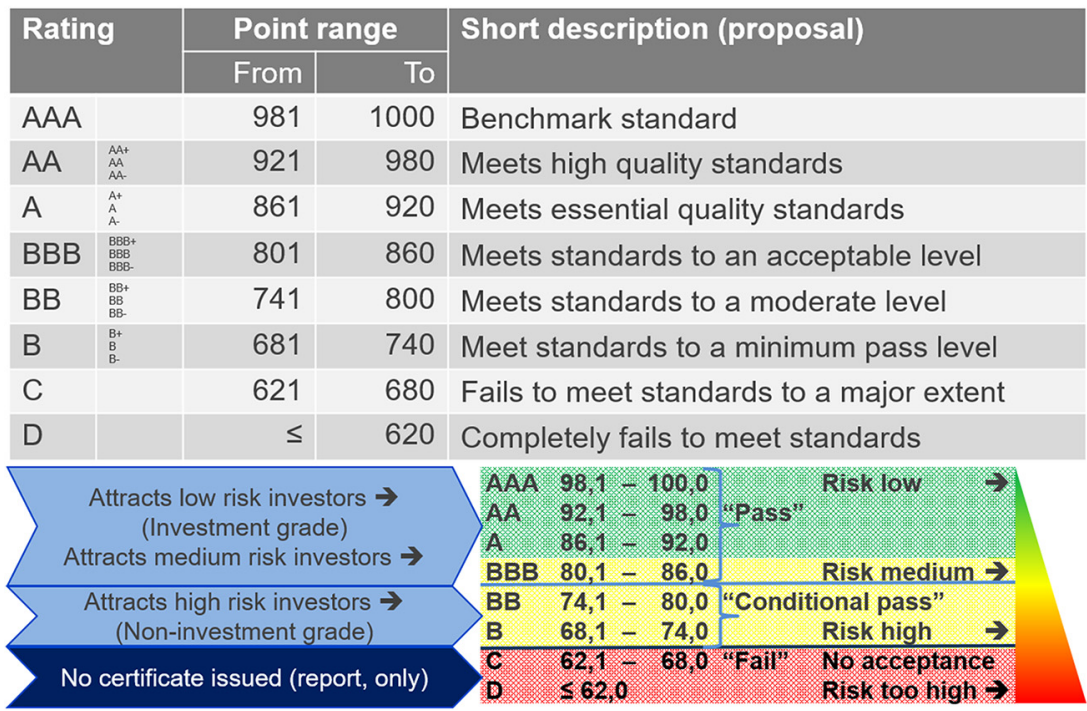

Fig. 8. Risk classification system (current draft).

project seems unavoidable. Supervising the actual online monitoring of performance data would intrude on operational management. Therefore, the operational management manual would be assessed prior to the commercial operation date, while data would be subject to assessment, e.g., during an annual performance review or in the event of an insured event. In either of these cases, the logbook and logged data would have to be made accessible by the owner and/or operator.

- Technical project rating: The basic ratings and the elements of project implementation monitoring result in a risk classification and performance assessment that results in a corresponding rating for the PV system concerned. This project rating should be designed in such a way that the insurance company can derive a risk calculation and subsequently an insurance premium from it.

The classification of a rating for a PV system would be interpreted analogously to Figure 8 for basic ratings.

The project rating can possibly also be relevant for calculating

- risk premiums and/or leverage limits for bank loans, and/or

- insurance premiums for general insurance products. 


\section{Concluding thoughts on risk mitigation and on PV power plant economics}

It is evident that a significant number of PV power plants underperform up to the point that the financial viability of the PV power plant project is at stake. The analysis of several thousand insurance claim cases reveals that internally caused damages represent approx. $20 \%$ of all claim cases, and equally importantly, that the amount of internally induced damages significantly increases with the service life of the PV power plant.

The continued reduction of levelized cost of electricity (LCOE) may be a cause provoking an increasing level of quality issues in the field. The only viable way to establish profitable business for all stakeholders at such levels of LCOE is to continue reducing actual costs while at the same time, implementing effective quality assurance practices. One important lever in this race to drive cost down at acceptable quality levels is to establish standards that are valid across the industry, including quality assurance standards. Minimum standards are about to be published by IECRE, and a rating system is on course to being developed, helping to assess the risk exposure that goes along with a PV power plant investment in a more effective and uniform way.

The author therefore recommends that investors, banks, and insurers seek the execution of higher, more consistent, and comprehensive degree of regular and recurring quality assurance and conformity assessments throughout the lifetime of a PV power plant, in line with internationally established - and still to be established - standards. More information can be queried by contacting the author.

Finally, in mature markets, standardization has proven to enlarge market potential that would have been impossible to address without having established standards, examples are the market penetration of IT systems or mobile telecommunication.

\section{References}

1. https://www.iecre.org/

2. Consortium project PVScan - Evaluation research of quality assurance and assessments of PV modules in solar power plants work package 5 titled current insurance products and detection of relevant data (original language: German), http://www. pvstatlab.rwth-aachen.de/index.php/PVScan-project.html 